\title{
Analysis of moisture and total sugar content of Huizao based on surface images
}

\author{
Junxiong Zhang ${ }^{1 *}$, Qingqing $\mathrm{Ma}^{1}$, Fen $\mathrm{He}^{2,3}$, Feng $\mathrm{Qu}^{1}$, Wei $\mathrm{Li}^{1}$ \\ (1. College of Engineering, China Agricultural University, Beijing 100083, China; \\ 2. Chinese Academy of Agricultural Engineering Planning and Design, Beijing 100125, China; \\ 3. Key Laboratory of Farm Building in Structure and Construction, Ministry of Agriculture and Rural Affairs, Beijing 100125, China)
}

\begin{abstract}
Moisture and total sugar content are two important internal qualities of Huizao. In order to explore their correlation with external qualities, a novel method of moisture and total sugar content analysis was proposed based on surface images. Firstly, five geometric features and seven texture features of Huizao were obtained to be the external quality indexes by digital image processing technology. Secondly, the wrinkle degree as an important index was extracted by marked watershed segmentation algorithm. According to the external quality the Huizao samples were grouped, and the moisture and total sugar content were determined through physical and chemical methods. Lastly, the moisture and total sugar content and twelve external indexes were all processed by step discriminatory analysis. Meanwhile, the regression models of moisture content with short diameter, contrast, and wrinkle degree and total sugar with wrinkle degree were established. The coefficients of the model were 0.9992 and 0.9978 respectively, and all the significance was less than 0.01 , which show that the regression equation and regression coefficient effect are highly significant. The results indicate that the moisture and total sugar content of Huizao are greatly correlated with the wrinkle degree. The moisture and total sugar content are the highest when the wrinkle degree is at 2 to 3 grade, and they decrease gradually with the wrinkle degree increasing. Moisture content shows positive correlation with the size of Huizao. The results of model analysis agree well with the experimental results, which can provide valuable reference for improving Huizao grade diversity.
\end{abstract}

Keywords: Huizao, step discriminatory analysis, moisture content, total sugar DOI: $10.25165 /$ j.ijabe.20181104.3386

Citation: Zhang J X, Ma Q Q, He F, Qu F, Li W. Analysis of moisture and total sugar content of Huizao based on surface images. Int J Agric \& Biol Eng, 2018; 11(4): 238-243.

\section{Introduction}

Moisture and total sugar content are the main indexes of dried Jujube internal quality ${ }^{[1]}$. Traditional methods for detecting fruits moisture and total sugar content mainly depend on physical and chemical analysis. Analyzing the material based on specific physical and chemical reactions and metrological relationships has the characteristics such as high precision, cumbersome operation, time-consuming, destructive and high reagents cost $\mathrm{t}^{[2,3]}$. Presently, many fast non-destructive testing technologies are gradually replacing the traditional chemical testing in some fields, especially, image processing technology based on machine vision has been widely used in the determination of moisture and total sugar content ${ }^{[4-7]}$. Wattanavicheanand et al. ${ }^{[8]}$ analyzed maturity of 'Kao Nampheung' pummelo by measuring both size and density of oil glands on the fruit surface with a developed image processing program. The experimental results showed that the average size and density of oil glands had positive and negative quadratic

\section{Received date: 2017-03-31 Accepted date: 2018-02-22}

Biographies: Qingqing Ma, MS, research interests: agricultural robotics and machine vision, Email: 18811782276@163.com; Fen He, PhD, research interests: agricultural engineering, Email: hefen_2005@163.com; Feng Qu, $\mathrm{PhD}$, research interests: agricultural robotics and machine vision, Email: 1012861156@qq.com; Wei Li, PhD, Professor, research interests: agricultural robotics Email: liww@cau.edu.cn.

*Corresponding author: Junxiong Zhang, PhD, Associate Professor, research interests: agricultural robotics and machine vision. College of Engineering, China Agricultural University, Beijing 100083, China. Tel: +86-13466369619, Email: cau2007@cau.edu.cn. correlation with fruit age, respectively. A vision sensing device was developed by the production system engineering laboratory of Okayama University in Japan, and the gradient filter was used to process the image of equipment to evaluate the surface glossiness of eggplant. Distinguishing various glossiness states of the fruit was made possible by analyzing the specular reflectance of the fruit surface $^{[9]}$. With the image texture eigenvalue analysis as the main technology, Li et al. ${ }^{[10]}$ explored a real-time measurement method of using process material image to show the moisture content of apple during freeze-drying process under vacuum freeze-drying condition, and proved that the moisture content can be monitored on line based on texture features of fruits and vegetables. The relative error of the model was less than $3 \%$.

There are few studies on the internal quality of dry Jujube with image processing technology, some researches are focused on the internal quality of fresh Jujube. Xue et al. ${ }^{[11]}$ tested the external natural damage and internal soluble solids content of Huping Jujube through models by using hyperspectral imaging technology. Lee et al. ${ }^{[12,13]}$ took with the size and maturity of Yezao as the grading indexes, in which the maturity index was determined by the surface color, and proposed a color space conversion and color distribution analysis technology. Linear calibration system of surface color and maturity was established and the robustness is relatively high.

The external characteristics of dried Jujube, such as color, shape and texture, are also the reflections of their internal quality ${ }^{[14]}$ How to extract the external characteristics of dry Jujube by effective methods, establish the correlation between external characteristics and internal quality, and reflect the internal quality 
of red dates based on the external characteristics is significantly important to reduce the difficulty of grading, improve the grading speed and increase the diversity of the grade. In this study, the correlation between moisture and total sugar content with surface texture characteristics of Huizao were explored under the same dry conditions, and step discriminatory analysis was proposed to analyze the total sugar and moisture content of Huizao to realize the fast non-destructive detection of Huizao internal quality.

\section{Materials and methods}

\subsection{Experimental set-up}

The experimental materials were 300 Xinjiang Akesu Ruoqiang Huizao without obvious defects, which were harvested in middle September 2016. The diameter of these Huizao samples was $18-28 \mathrm{~mm}$ and the surface texture differed from smooth to wrinkle. In order to avoid the impacts of external environmental variables on the quality of Huizao, all the samples' conditions were the same, such as varieties, origin place, climate, cultivation and dry conditions. The instrument used was composed of three parts: 1) Image acquisition device: MER-200-14GC color CCD camera with frame rate $14 \mathrm{fps}$, OPT-C2514-5M lens with $\mathrm{f} 25 \mathrm{~mm}$ and F1.4, OPT- RIA211 color LED ring light source; 2) Moisture detection equipment: HB43-S compact halogen moisture detector produced by METTLER TOLEDO Company; 3) Total sugar measurement equipment: thermostatic water bath, thermostat electric furnace, beater and some chemical reagents.

\subsection{Measurements}

\subsubsection{External quality detection}

The external quality of Huizao mainly includes geometric features (long diameter, short diameter, circumference, area, fruit shape index, etc.) and texture features (wrinkle degree). These external quality indexes were realized by digital image processing based on MATLAB platform.

Firstly, the 300 Huizao samples were numbered from No.1 to No.300. Then the environment and parameters of the image acquisition device were adjusted: object distance is $25 \mathrm{~cm}$, light intensity is $35000 \mathrm{~lx}$, and exposure time is $2250 \mu \mathrm{s}$. In this study, the complementary light theory was used to capture the images of Huizao under cyan light environment. In order to collect the texture information of the entire surface of Huizao as much as possible, three images of each Huizao were collected, which can show the entire surface of Huizao, and the average value of the three images represents the information of one whole Huizao. The specific image processing is shown in Figure 1.
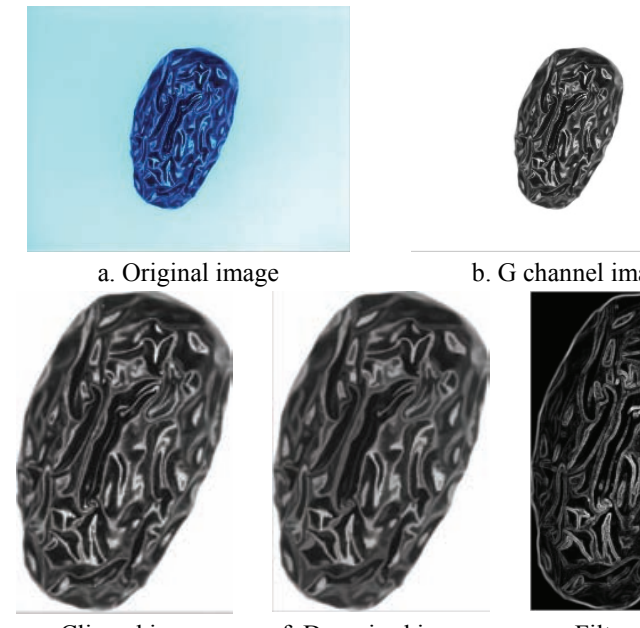

e. Clipped image

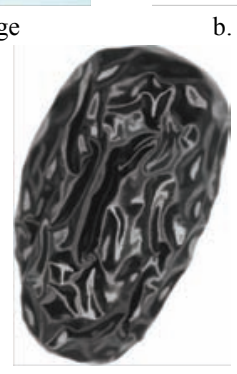

b. G channel image

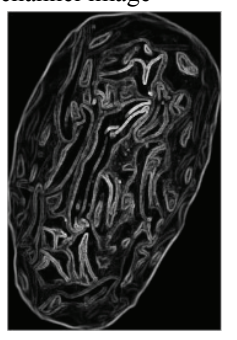

g. Filtered image

\section{(1) Geometric features}

The binary processing (Figure 1c) of the fixed threshold $(T=$ 200) was performed by the G (Green) channel (Figure 1b) of the original image (Figure 1a), and the length and width of target area minimum enclosing rectangle ${ }^{[15]}$ (Figure 1d) approximately represent long diameter $L$ and short diameter $W$ of each Huizao, the shape index is the ratio of long diameter to short diameter.

The circumference $P$ of Huizao is the sum of all the pixels in the contour, and the area $A$ is the number of all the pixels in the target area.

(2) Texture features

The three principal approaches used in image processing to describe the texture of a region are statistical, structural, and spectral. Statistical approaches yield characterizations of textures as smooth, coarse, grainy, and so on. Structural techniques deal with the arrangement of image primitives, such as the description of texture based on regularly spaced parallel lines. Spectral techniques are based on properties of the Fourier spectrum and are used primarily to detect global periodicity in an image by identifying high-energy, narrow pecks in the spectrum ${ }^{[16]}$. The texture of Huizao is irregular and there is no periodic, so the texture analysis method based on the statistical properties of brightness histogram was chosen. The main manifestation of Huizao texture is uneven wrinkle on the surface, which is a space texture. Based on this property of Huizao texture, a method to describe the texture of Huizao was proposed based on the marked watershed segmentation algorithm ${ }^{[17-20]}$ for extracting wrinkle area.

The background of the original image occupies too much area. In order to minimize the amount of information to be processed and to increase the speed of the algorithm, the G-channel gray-scale image was clipped along the external rectangle, which is the binarized Huizao contour, and the clipped image is shown in Figure 1e. Morphology denoising (Figure 1f) and local range filtering (gradient amplitude image Figure 1g) were performed on the clipped images. Foreground mark (Figure 1h) and background mark (Figure 1i) were processed on the denoised images, and then the magnitude image was modified to the final segmentation function by the minima imposition of the marked image area, and finally the watershed segmentation (Figure 1j) was performed. The wrinkle of Huizao was finally marked in the form of regions, and the wrinkle degree was described by the number of regions.

The mean, contrast, $\mathrm{R}$ (normalized red component), third moment, uniformity, entropy and wrinkle degree were used as seven indexes to measure the texture information of the Huizao.

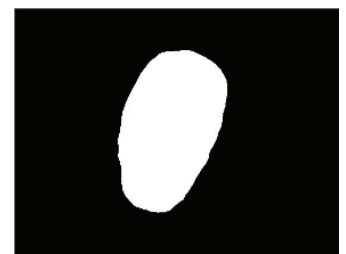

c. Binary image

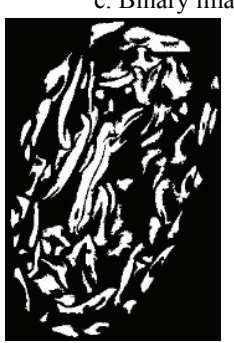

h. Target markers

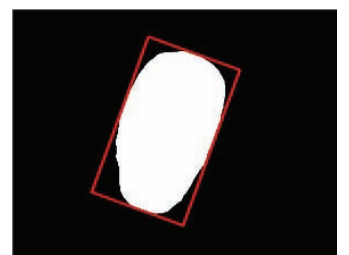

d. Minimum enclosing rectangle

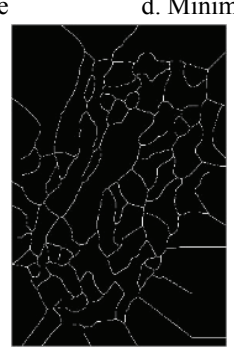

i. Background markers

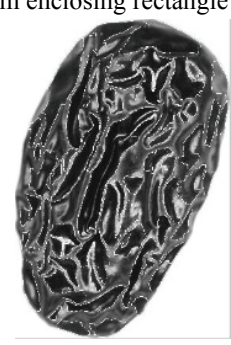

j. Segmented image

Figure 1 Acquisition algorithm of external qualities 


\subsubsection{Internal quality testing}

The weight of single Huizao pulp is about 1.94-7.17 g, which is not enough to measure the moisture content and total sugar at the same time. It is necessary to classify all the Huizao samples, and the principle of classification is to make the external quality of Huizao in the same group as close as possible.

First of all, taking the wrinkle degree as the classification index, all Huizao samples were divided into 6 grades by using the K-Mean clustering algorithm ${ }^{[21]}$ (Figure 2a). The descriptive frequency statistics of wrinkle degree of all Huizao samples was carried out, as shown in Figure $2 b$, the results tended to the Gaussian distribution. Therefore, the number of subclasses of each grade should also be different. Then, the clustering analysis of each grade was processed based on the comprehensive indicators of geometric characteristics. At last, after removing the Huizao that cannot be in a separate group, all the rest Huizao were divided into 29 groups. The number of 6 grades is $3,6,7,5,5$ and 3 respectively. The kernels of Huizao were cut out by knife, and the pulp was diced into ground pulp, which were mixed in sealed bags, and then 29 samples were obtained.

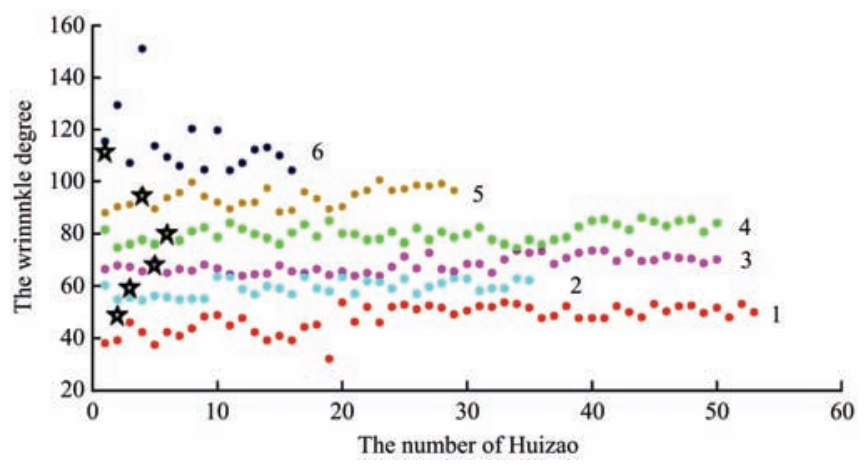

a. Clustering and classification of Huizao

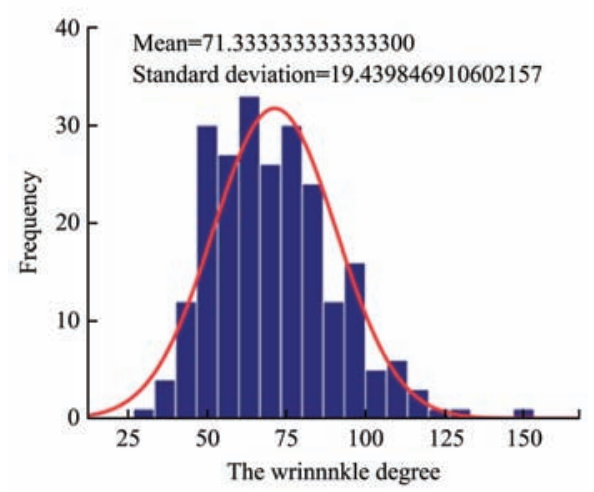

b. Descriptive statistics of the wrinkle degree

Figure 2 Charts analysis on the index of wrinkle degree of Huizao

The moisture content of Huizao was measured by HB43-S compact halogen moisture detector. When detecting, clean aluminum sample plate was put into the detector and the detector was calibrated and returned to zero automatically. Picking $3 \mathrm{~g}$ Huizao samples into the aluminum sample plate and the instrument started heating automatically. When it was heated to the maximum temperature of $105^{\circ} \mathrm{C}$ and the number was stable, the moisture content was recorded.

Total sugar content was tested according to GB/T $10782-2006^{[22]}$. The principle is to calibrate the Fehling reagent and $10 \mathrm{~mL}$ Fehling mixture is determined to be equivalent to the quality of the glucose. The Fehling mixture solution was added to Huizao immersion filtrate to do the titration, and the total sugar content in the sample was calculated by the volume of the test solution, the mass of the sample, the dilution ratio and the $10 \mathrm{~mL}$ Fehling mixture equal to the glucose quality. The calculation formula is:

$$
X_{1}=\frac{A \times 6250}{m \cdot V} \times 100
$$

where, $X_{1}$ is total sugar content in the sample, $\mathrm{g} / 100 \mathrm{~g} ; A$ is $10 \mathrm{~mL}$ Fehling mixture that equals to the glucose quality, $g ; m$ is the quality of the sample, $\mathrm{g} ; V$ is the volume of the test solution consumed during the titration , $\mathrm{mL} ; 6250$ was the dilution ratio.

\section{Results and discussion}

\subsection{Experimental results}

Based on the test results, taking size and wrinkle degree as the independent variables, the qualitative analysis of the moisture content and the total sugar change was carried out, and it was shown in Figure 3. The moisture content is related to the size of Huizao. The larger the size, the higher the moisture content is. However, there is no obvious correlation between the total sugar content and the size. The moisture content and total sugar of Huizao are the highest when the wrinkle degree is between grade 2 and grade 3, and then decrease while the wrinkle degree increases. The Huizao in grade 1 have the highest degree of R (normalized), but the moisture content and total sugar content are relatively low, which is due to fruit plumpness and low elasticity caused by early picking.

\subsection{Step discriminatory analysis}

Step discriminatory analysis ${ }^{[23]}$ is a multivariate statistical analysis method, which is a process of continuous screening variables and repeating "introduction" and "elimination" of the variables. Every time when one of the most important variables is introduced, it is checked whether the previously introduced variable becomes non-significant with the introduction of the new variable, and the variable that is not significant in the discriminant is eliminated. The process repeats till all the variables in the discriminant are very significant and there are not variables that influence the significance. Step discriminatory method is with small amount of analysis and calculation and good practical results. It is still a widely used variable selection method.

The external quality of all the Huizao in one sample are almost the same, so the average value of each external quality of each sample is taken as the external quality value of the sample, and 29 sets of data are formed with the measured moisture and total sugar content. In the IBM SPSS Statistics v21 environment, the results in Table 1 were obtained by step discriminatory analysis with 12 quality indexes as the independent variables and moisture content and total sugar as the dependent variables. It can be seen that the wrinkle degree contributes the most to the total sugar content, which indicates that the total sugar is mainly related to the texture index. The moisture content is mostly bound up with the short diameter, wrinkle degree and the contrast, which shows that the moisture content is related to the geometric and texture indexes.

(1) Moisture content analysis

The moisture content, short diameter, contrast and wrinkle degree were analyzed by multiple nonlinear regression analysis. According to the idea of "transforming nonlinearity into linearity", the ternary polynomial fitting was carried out, and the number of polynomials is gradually increased and finally the model is ternary cubic polynomial:

$$
S=a_{1} N+a_{2} N^{2}+a_{3} N^{3}+a_{4} c N+a_{5} W N+a_{6} W c N
$$




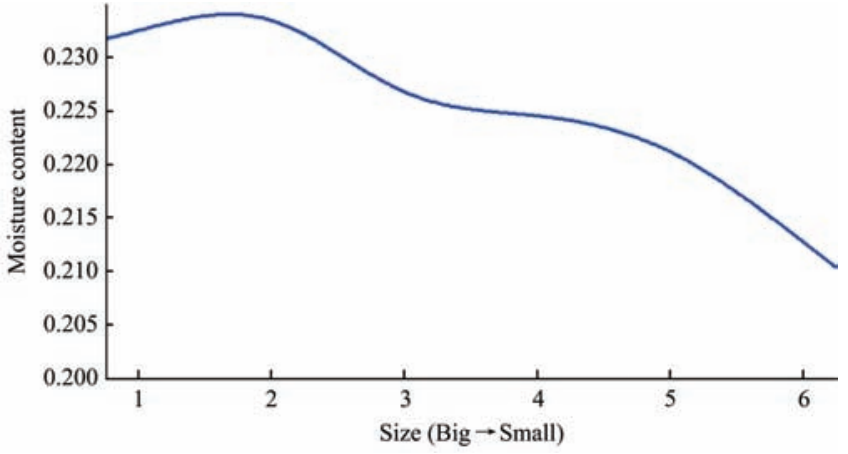

a. Moisture content (size)

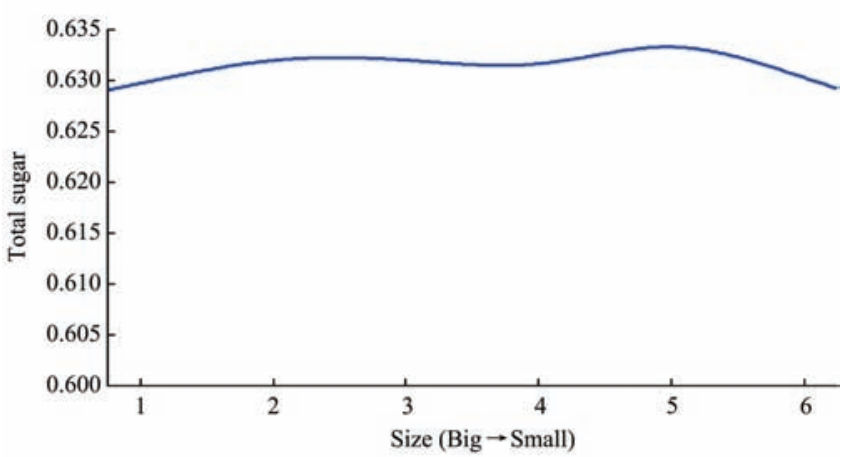

b. Total sugar (size)

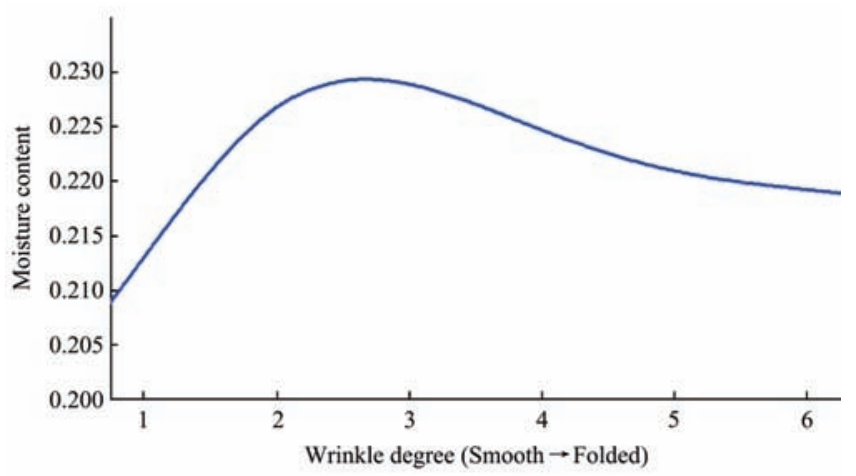

c. Moisture content (wrinkle degree)

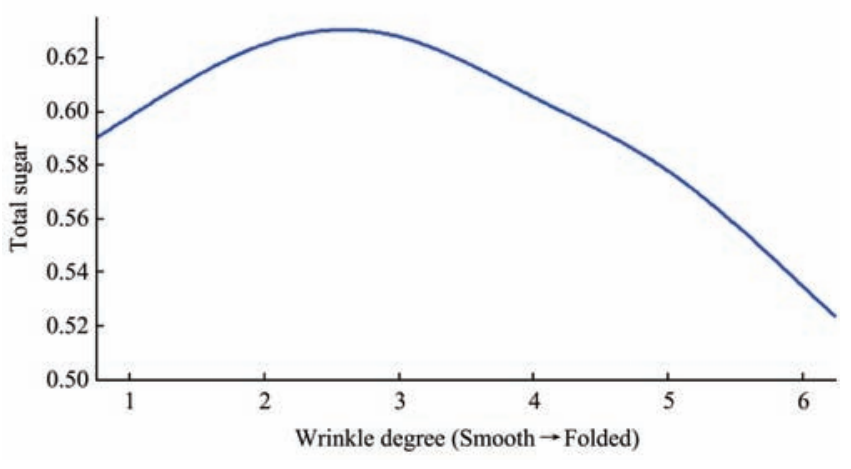

d. Total sugar (wrinkle degree)

Figure 3 Correlation curves of moisture content, total sugar and size, wrinkle degree

Table 1 Results of step discriminatory analysis

\begin{tabular}{ccccc}
\hline $\begin{array}{c}\text { Dependent } \\
\text { variable }\end{array}$ & Model & $\begin{array}{c}\text { Input } \\
\text { variables }\end{array}$ & $\begin{array}{c}\text { Exact } \\
\text { quantity }\end{array}$ & Method \\
\hline $\begin{array}{c}\text { Moisture } \\
\text { content }\end{array}$ & 1 & Short diameter & & $\begin{array}{c}\text { Stepping (criterion: Probability } \\
\text { of } F \text {-to-enter } \leq 0.050 \text {, Probability } \\
\text { of F-to-remove } \geq 0.100)\end{array}$ \\
\hline Total Sugar & 1 & Wrinkle & - & $\begin{array}{r}\text { Stepping (criterion: Probability } \\
\text { of } F \text {-to-enter } \leq 0.050, \text { Probability } \\
\text { of } F \text {-to-remove } \geq 0.100)\end{array}$ \\
\hline
\end{tabular}

The model of moisture content after fitting is:

$$
\begin{aligned}
S= & -0.02159 N-0.00014 N^{2}+0.000371 N^{3}+0.012422 W N- \\
& 0.00015 c N+5.75 \times 10^{-7} W c N
\end{aligned}
$$

where, $a_{1}, a_{2}, a_{3}, a_{4}, a_{5}, a_{6}$ are polynomial coefficients; $c$ is standard deviation; $N$ is wrinkle degree; $W$ is short diameter, $\mathrm{mm} ; S$ is moisture content.

The fitting results are listed in Table 2, the residual error of all data is in the interval range of -0.02 to 0.015 . And the distribution is shown in Figure 4. The correlation coefficient $R^{2}$ is 0.9992 which shows that all the variation of the moisture content can be explained with the three indexes by the regression relation. The value of insignificance $\mathrm{F}$ is close to zero, and the regression equation fitting and regression coefficient are extremely significant.

Table 2 Results of non-linear regression of moisture content

\begin{tabular}{ccccc}
\hline $\begin{array}{c}\text { Regression } \\
\text { analysis }\end{array}$ & $\begin{array}{c}\text { Regression } \\
\text { terms }\end{array}$ & $\begin{array}{c}\text { Parameter } \\
\text { estimation }\end{array}$ & $\begin{array}{c}\text { Significance test } \\
\text { probability } P\end{array}$ & $\begin{array}{c}\text { Determination } \\
\text { coefficient } R^{2}\end{array}$ \\
\hline \multirow{2}{*}{$F=5320.391$} & $N$ & -0.02159 & 0.00795 & \\
& $N^{2}$ & -0.00014 & $4.17 \mathrm{E}-14$ & \\
Significance & $N^{3}$ & 0.00037 & 0.00053 & 0.9992 \\
$F=1.29 \mathrm{E}-33$ & $W N$ & 0.01242 & 0.00063 & \\
& $c N$ & -0.00015 & 0.00083 & \\
& $W c N$ & $5.75 \mathrm{E}-07$ & $1.93 \mathrm{E}-10$ & \\
\hline
\end{tabular}

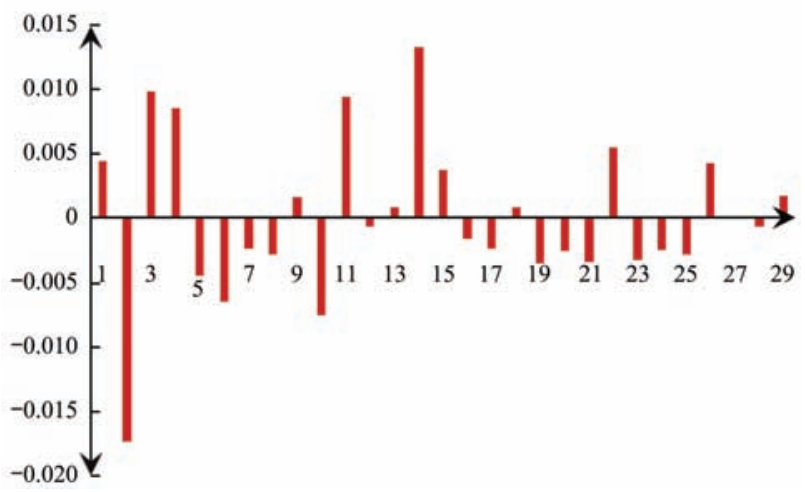

Figure 4 Residual plot of moisture content

(2) Total sugar analysis

A preliminary curve of the total sugar-wrinkle degree was estimated with SPSS and it is shown in Figure 5. By combining the fitting situation of all the curves in the picture and comparing to the ANOVA table, it is concluded that the cubic function model can better reflect the correlation between the total sugar and wrinkle degree. Therefore, cubic curve fitting was done between the total sugar and wrinkle degree, and the fitting results are shown in Table 3 (before correction). $R^{2}$ is 0.5778 , indicating that the total sugar can't be explained by wrinkle degree well. Significance $F$ is $6.66 \times 10^{-5}$, which is less than 0.05 , shows that the regression equation is significant. Seen from the model coefficient, only the standard error of the constant term is relatively large and the probability value $P$ is 0.8758 , lager than 0.05 , which illustrates that the constant term of the regression coefficient is not significant and the regression model needs to be modified. On the premise that the regression model is significant and the mismatch term is not significant, and on the principle that significance influence value $P$ should be smaller and the extremely non-significant items are removed, the regression model was cleared and a new regression model was obtained after refitting the curve:

$$
T=0.02544 N-0.00032 N^{2}+1.2410^{-6} N^{3}
$$

where, $T$ is total sugar; $N$ is wrinkle degree. 
The statistics of testing the regression model is shown in Table 3 (after correction). The correlation coefficient $R^{2}$ is 0.9987 after correction. The model fitting degree is very high. The F value, which is to test the significance of regression variance, increases rapidly. Significance $F$ is about 0 and it is much less than 0.05 . The regression equation effect and the regression coefficient are improved significantly.

Table 3 Results of non-linear regression of total sugar

\begin{tabular}{|c|c|c|c|c|c|}
\hline & & $\begin{array}{l}\text { Regression } \\
\text { terms }\end{array}$ & $\begin{array}{l}\text { Parameter } \\
\text { estimation }\end{array}$ & $\begin{array}{l}\text { Significance test } \\
\text { probability } p\end{array}$ & $\begin{array}{l}\text { Determination } \\
\text { coefficient } R^{2}\end{array}$ \\
\hline \multirow{4}{*}{$\begin{array}{l}\text { Before } \\
\text { correction }\end{array}$} & $F=11.4089$ & $\begin{array}{l}\text { constant } \\
\text { term }\end{array}$ & 0.0308 & 0.8758 & \multirow{4}{*}{0.5778} \\
\hline & \multirow{3}{*}{$\begin{array}{l}\text { Significance } \\
F=6.66 \mathrm{E}-05\end{array}$} & $N$ & 0.0241 & 0.0068 & \\
\hline & & $N^{2}$ & -0.0003 & 0.0099 & \\
\hline & & $N^{3}$ & $1.17 \mathrm{E}-06$ & 0.0190 & \\
\hline \multirow{4}{*}{$\begin{array}{c}\text { After } \\
\text { correction }\end{array}$} & $F=6725.491$ & $\begin{array}{c}\text { constant } \\
\text { term }\end{array}$ & 0 & - & \multirow{4}{*}{0.9987} \\
\hline & \multirow{3}{*}{$\begin{array}{l}\text { Significance } \\
F=1.86 \mathrm{E}-36\end{array}$} & $N$ & 0.0254 & $1.3 \mathrm{E}-21$ & \\
\hline & & $N^{2}$ & -0.0003 & $2.66 \mathrm{E}-14$ & \\
\hline & & $N^{3}$ & $1.24 \mathrm{E}-06$ & $5.61 \mathrm{E}-10$ & \\
\hline
\end{tabular}

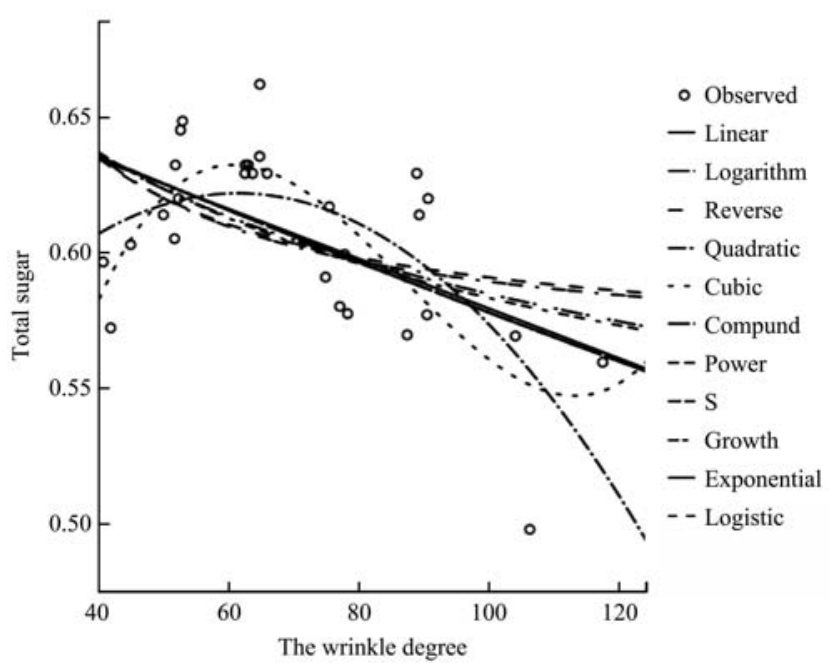

Figure 5 Curve estimation of total sugar-wrinkle degree

\subsection{Model analysis}

In the moisture content model, the variables of diameter and contrast were fixed, and $S-N$ shows a cubic function relationship. When $S$ is the maximum value, $\mathrm{N}$ value is between grade 2 and grade 3. With the contrast and the wrinkle degree as two fixed variables, $S$ - $W$ shows positive correlation, that is, the larger Huizao has higher moisture content. In the total sugar content model, the highest point of the total sugar is between the wrinkle degree of grade 2 and grade 3, and then it decreases as the degree of wrinkle increases. The results of the model analysis are consistent with the previous experimental analysis results. The larger and smoother Huizao has better internal quality.

\section{Conclusions}

With the digital image processing as the main technical method, the correlation analysis between internal moisture content, total sugar content and external twelve quality indexes was carried out by using the step discriminatory analysis, and mathematical models of the moisture content, the total sugar and significantly related external indexes were established. The results show:

(1) The moisture content is related to the short diameter, contrast and wrinkle degree. For the Huizao with about the same size, the smoother surface, the higher moisture content is. For the Huizao with about the same wrinkle degree, the larger one has higher moisture content.

(2) The total sugar content is mainly related to the wrinkle degree, and the correlation is in accordance with the cubic function model. The Huizao with 2 to 3 wrinkle degree has more sugar, and the total sugar gradually reduces as the degree of wrinkle increases.

(3) The fitting effect of the two models is relatively good, and the regression coefficient is significant, which can fully reflect the correlation between the moisture content, the total sugar content and the external quality. The results of the model analysis are in good agreement with the experimental results.

\section{Acknowledgments}

The authors acknowledge that this research was financially supported by the National Key Research and Development Plan: Intelligent harvesting mechanism research and new structure development of special agricultural products (Grant No.2016YFD0701501).

\section{[References]}

[1] GB/T 5835-2009, Dried Chinese jujubes. (in Chinese)

[2] Suherman P M, Peter M T, Geoff Smith. Development of a remote electrode system for monitoring the water content of materials inside a glass Vial. Pharmaceutical Research, 2002; 19(3): 337-344.

[3] Naoto N, Hideki O, Satoshi W, Sayaka S. Study of sugar transformations in carrots during storage using snow by Mid-Infrared spectroscopy and chemometrics. Applied Spectroscopy: Society for applied spectroscopy, 2012; 66(9): 1087-1090.

[4] Han W, Sun Y, Xu T F, Chen X W, Su K O. Detecting maize leaf water status by using digital RGB images. Int J Agric \& Biol Eng, 2014; 7(1): 45-53.

[5] Qi H J, Jin X, Zhao L, Dedo I M, Li S W. Predicting sandy soil moisture content with hyperspectral imaging, Int J Agric \& Biol Eng, 2017; 10(6): 175-183.

[6] Jie D F, Xie L J, Rao X Q, Ying Y B. Using visible and near infrared diffuse transmittance technique to predict soluble solids content of watermelon in an on-line detection system. Postharvest Biology and Technology, 2014; 90: 1-6.

[7] Cunha M, Carvalho C, MarcalA R S. Assessing the ability of image processing software to analyze spray quality on water-sensitive papers used as artificial targets. Biosystems Engineering, 2012; 111(1): 11-23.

[8] Wattanavicheanand K, Aroonyadet N. Assessment of fruit maturity in 'Kao Nampheung' pummelo using image processing of oil glands. Thai Journal of Agricultural Science, 2003; 36(2): 129-140.

[9] Chong V K, Nishi T, Kondo N, Monta M, Namba K, Zhang Q, Shimizu H Surface gloss measurement on eggplant fruit. Applied Engineering in Agriculture, 2008; 24(6): 877-883.

[10] Li X B, Guo Y M, Fu L H. On-line monitoring of moisture ratio for apple during vacuum freeze-drying based on image texture analysis. Transactions of the CSAM, 2012; 28(21): 229-235. (in Chinese)

[11] Xue J L, Zhang S J, Zhang J J. Simultaneous detection of external and internal quality parameters of Huping jujube fruits using hyperspectral imaging technology. Spectroscopy and Spectral Analysis, 2015; 35(8): 2297-2302. (in Chinese)

[12] Lee D-J, Archibald J K, Chang,Y-C Greco C R. Robust color space conversion and color distribution analysis techniques for date maturity evaluation. Journal of Food Engineering, 2008; 88(3): 364-372.

[13] Lee D-J, Schoenberger R, Archibald J, McCollum S. Development of a machine vision system for automatic date grading using digital reflective near-infrared imaging. Journal of Food Engineering, 2008; 86: 388-398.

[14] Luo H P, Lu Q P. Application of near-infrared topology method in the quality analysis of jujube of southern Xinjiang. Spectroscopy and Spectral Analysis, 2012; 32(3): 655-659. (in Chinese)

[15] Ying Y B, Wang J P, Jiang H Y. Inspecting diameter and defect area of 
fruit with machine vision. Transactions of the CSAM, 2002; 18(5): 216-220. (in Chinese)

[16] Gonzalez R C, Woods R E. Digital Image Processing Second Edition. New Jersey: Prentice Hall Press, 2002; pp.665-666.

[17] Zhang J X, Ma Q Q, Li W, Xiao T T. Feature extraction of jujube fruit wrinkle based on the watershed segmentation. Int J Agric \& Biol Eng, 2017; 10(4): 165-172.

[18] Jones G. Image segmentation using texture boundary detection. Pattern Recognition Letters, 1994; 15(6): 533-541.

[19] Soille P. Morphological Image Analysis Principles and Applications. New York: Springer-Verlag Press. 2008; pp.150-152.
[20] Li X L, Ma Z H, Fernando B, Qin F, Wang H G, Jose A A. Development of automatic counting system for urediospores of wheat stripe rust based on image processing. Int J Agric \& Biol Eng, 2017; 10(5): 134-143.

[21] Siddiqui F U, Matisa N A. Optimized $K$-means (OKM) clustering algorithm for image segmentation. Opto-Electronics Review, 2012; 20(3): 216-225.

[22] GB/T 10782-2006, General rule for preserved fruits. (in Chinese)

[23] Siddiqi M H, Ali R, Khan A M, Park Y-T, Lee S. Human facial expression recognition using stepwise linear discriminant analysis and hidden conditional random fields. IEEE Transactions on Image Processing, 2015; 24(4): 1386-1398. 